\title{
Rancang Bangun Sistem Pengukuran Kadar Alkohol Dan Suhu Berbasis Mikrokontroler Arduino UNO Untuk Destilasi Minuman Beralkohol
}

\author{
Verna Albert Suoth a*, Handy Indra Regain Mosey a* \\ aJurusan Fisika, FMIPA, Unsrat, Manado
}

KATA KUNCI

Sensor LM35, Sensor MQ-3.

Mikrokontroler Arduino Uno.

\begin{abstract}
A B S T R A K
Dalam proses destilasi minuman tradisional beralkohol terdapat parameter fisis yang penting untuk diukur yakni suhu dan kadar alkohor. Pengukuran ini bertujuan untuk mengukur besaran fisis menjadi besaran yang terukur. Tujuan penelitian ini adalah untuk membuat alat ukur suhu dan kadar alkohol untuk digunakan pada saat proses penyulingan berlangsung. Kegiatan ini dimulai dengan rancang bangun alat ukur dengan menggunakan dua buah sensor yakni LM35 sebagai sensor suhu dan MQ-3 sebagai sensor alcohol. Kemudian pembacaan sensor ini dihubungkan ke sistem akusisi data menggunakan Mikrokontroler Arduino UNO dan ditampilkan pada LCD. Alat ini kemudian di uji dengan membandingkan hasil pengukuran dengan alat ukur yang lain, dari hasil diperoleh pada pengukuran suhu terdapat selisi pengukuran rata-rata $0.1^{\circ} \mathrm{C}$ sedangkan untuk pengukuran kadar alcohol di peroleh selisih pengukuran rata-rata $1 \%-3 \%$, sedangkan kesalahan relatif alat yang dibuat adalah 3,25\%.
\end{abstract}

KEYWOR D S

Sensor LM35, Sensor MQ-3. Arduino Uno Microcontroller.
A B S T R A C T

In the process of distillation of traditional alcoholic beverages there are important physical parameters to measure i.e the temperature and the concentration alcohol. This measurement is intended to measure physical quantities into measurable quantities. This research is to develop an instrument to measure the temperature and the alcohol concentration during the distillation process. This research are began with designing the instrument employing two sensors i.e LM35 as temperature sensor and MQ-3 as alcohol sensor. Then the sensor readings is connected to a data acquisition system using the Arduino UNO Microcontroller and displayed on the LCD. The instrument then tested by comparing the measurement results with standard measurement tools, from the results obtained by the instrument there are a slight difference of $0.1^{0} \mathrm{C}$ while the alcohol concentration has a difference of $1 \%-3 \%$, while the relative error are $3.25 \%$.

\begin{tabular}{l}
\hline TERSEDIA ONLINE \\
\hline 01 Agustus 2016 \\
\hline
\end{tabular}

\section{Pendahuluan}

Pengukuran merupakan kegiatan yang dilakukan untuk menentukan besaran fisis dari suatu benda atau gejala tertentu. Pengukuran menjadi salah satu aktifitas yang selalu dilakukan manusia dalam kehidupan setiap hari. Berbagai instrumen pengukuran juga telah menjadi bagian yang lekat dalam aktifitas kehidupan manusia.

Dalam dunia industri, pengukuran yang presisi dibutuhkan dalam menentukan kualitas dari produk yang dihasilkan maupun dalam menjaga keberlangsungan proses industri itu sendiri. 
Destilasi adalah teknik untuk memisahkan larutan ke dalam masing-masing komponennya. Prinsip destilasi adalah didasarkan atas perbedaan titik didih komponen zatnya. Destilasi dapat digunakan untuk memurnikan senyawa-senyawa yang mempunyai titik didih berbeda sehingga dapat dihasilkan senyawa yang memiliki kemurnian yang tinggi. Berbagai jenis destilasi digunakan dalam industri untuk menghasilkan produk seperti, produk turunan minyak bumi, minyak atsiri dan alkohol.

Karena prinsip destilasi didasarkan pada perbedaan titik didih komponen larutannya, maka dalam proses destilasi, suhu menjadi salah satu faktor penentu. Pengukuran dan pengaturan suhu dalam proses destilasi, menentukan tingkat kemurnian produk destilasi yang akan dihasilkan. Seperti dalam proses destilasi alkohol, persentase kemurnian alkohol yang akan dihasilkan dapat ditentukan dengan pengaturan suhu pada proses pemanasan bahan baku.

\section{Material dan Metode}

Desain dan konstruksi alat ukur suhu dan kadar alkohol dilaksanakan pada bulan Maret - Mei 2016 di Laboratorium Fisika Material dan Energi Terbarukan Universitas Sam Ratulangi.

Penelitian dimulai dengan pembuatan desain rangkaian alat ukur suhu dan kadar alkohol. Kemudian dilakukan pembuatan rangkaian pengkondisi sinyal untuk sensor LM35 dan sensor MQ-3. Rangkaian sensor dan pengkondisi sinyal kemudian dihubungkan pada sistem akusisi data menggunakan arduino uno dan terhubung pada LCD. Kemudian alat ukur ini dilakukan pengujian pengukuran suhu dan pengukuran kadar alkohol dengan menggunakan alat ukur pembanding dan jika terdapat selisih pengukuran maka alat ukur ini dikalibrasi pada sistem rangkaian tersebut.

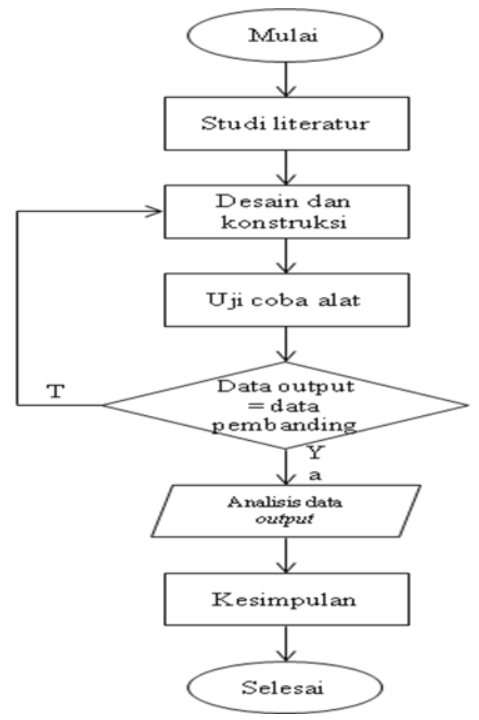

Gambar 1 Diagram alir Prosedur kerja

\section{Hasil dan Pembahasan}

\subsection{Perancangan Alat Ukur}

Perancangan alat ukur suhu dan kadar alcohol adalah sebagai berikut :

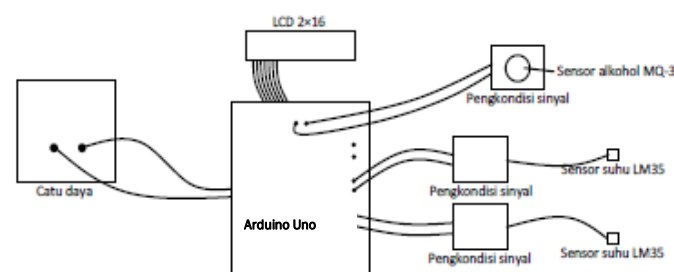

Gambar 2. Rancangan alat ukur suhu dan kadar alkohol pada destilasi minuman beralkohol

Sensor LM35 akan mendeteksi perubahan suhu pada saat proses destilasi dan sensor MQ-3 akan mendeteksi kadar alkohol hasil destilasi. Pengkondisi sinyal akan menyesuaikan tegangan dari sensor yang masuk ke mikrokontroler untuk diproses menjadi data. Data hasil keluaran mikrokontroler akan ditampilkan melalui LCD. Gambar dibawah ini merupakan rangkaian skematik alat ukur dengan menggunakan sistem minimum mikrokontroler Arduino Uno.

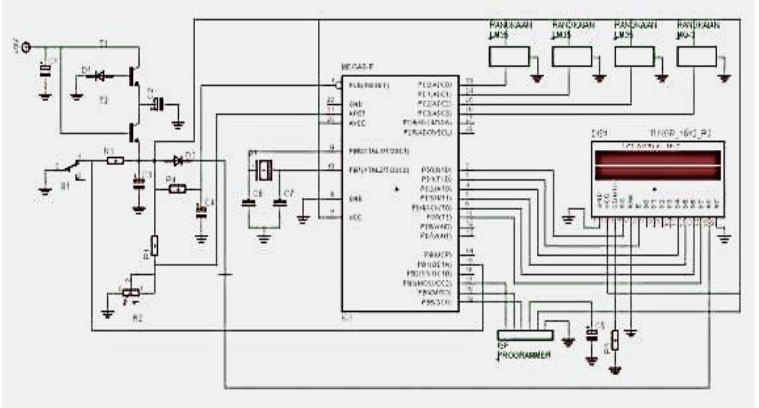

Gambar 3. Diagram Skematik alat ukur suhu dan kadar alcohol menggunakan Arduino Uno

\subsection{Pembuatan Sistem Pengkondisi Sinyal Sensor}

Rangkaian pengkondisi sinyal pada sensor suhu LM35 dan sensor alkohol MQ-3 merupakan berfungsi untuk mengubah level sinyal listrik ke level yang lain, agar sinyal tersebut dapat di akusisi dengan baik oleh sebuah mikrokontroler. Sistem pengkondisi sinyal pada setiap sensor tentu berbeda-beda, gambar dibawah ini menunjukan sistem pengkondisi sinyal baik pada sensor suhu LM35 dan sensor alcohol MQ-3.

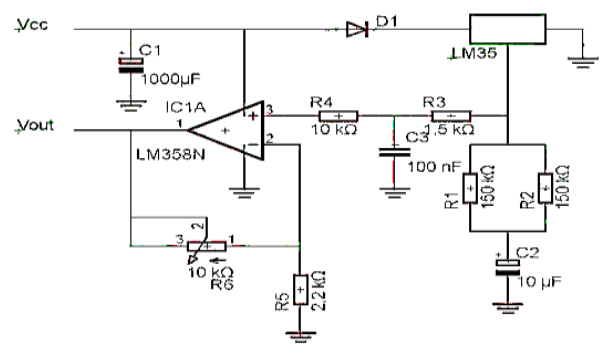

Gambar 4. Rangkaian Skematik Pengkondisi sinyal sensor suhu LM35 


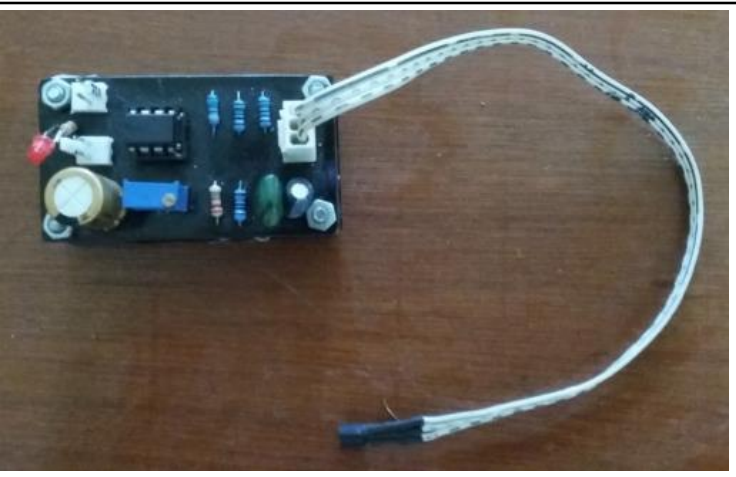

Gambar 5. Alat sensor suhu LM35

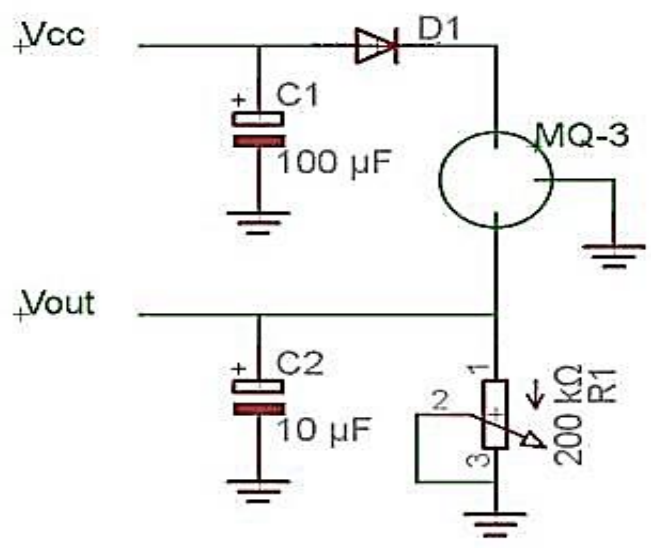

Gambar 6. Rangkaian Skematik Pengkondisi Sinyal Sensor Alkohol MQ-3

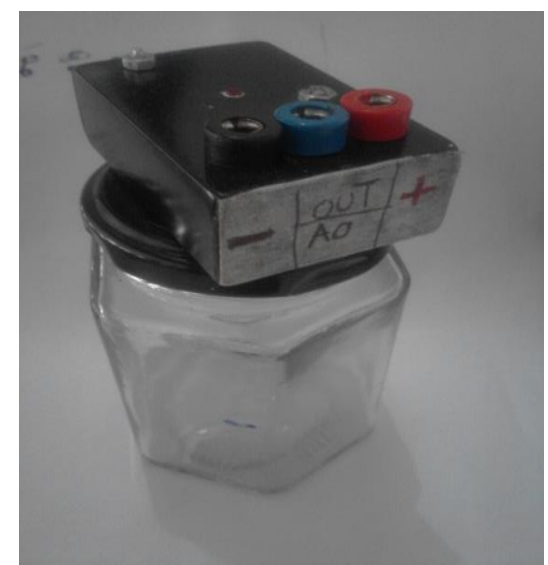

Gambar 7. Alat Sensor Alkohol MQ-3

\subsection{Hasil Pengujian Suhu}

Pengujian pengukuran suhu oleh alat ukur suhu dilakukan pada rentang suhu $30^{\circ} \mathrm{C}$ sampai $100^{\circ} \mathrm{C}$ dengan menggunakan medium air yang akan di panaskan hingga mencapai titik didih air, bersamaan dengan proses pemanasan air, sensor suhu bersama termometer diletakkan kedalam air, hasil pengukuran suhu seperti pada tabel dibawah ini.

Tabel 1. Hasil Pengujian Suhu
\begin{tabular}{|l|l|l|l|}
\hline No & Termometer & $\begin{array}{c}\text { Sensor } \\
\text { LM35 }\end{array}$ & Selisi \\
\hline 1 & 30,0 & 30,0 & 0,0 \\
\hline 2 & 35,0 & 34,9 & 0,1 \\
\hline 3 & 40,0 & 40,0 & 0,0 \\
\hline 4 & 45,0 & 45,0 & 0,0 \\
\hline 5 & 50,0 & 50,0 & 0,0 \\
\hline 6 & 55,0 & 54,9 & 0,1 \\
\hline 7 & 60,0 & 60,0 & 0,0 \\
\hline 8 & 65,0 & 64,9 & 0,1 \\
\hline 9 & 70,0 & 70,1 & 0,1 \\
\hline 10 & 75,0 & 74,7 & 0,3 \\
\hline 11 & 80,0 & 79,7 & 0,3 \\
\hline 12 & 85,0 & 84,6 & 0,4 \\
\hline 13 & 90,0 & 89,8 & 0,2 \\
\hline 14 & 95,0 & 95,0 & 0,0 \\
\hline 15 & 100,0 & 100,0 & 0,0 \\
\hline
\end{tabular}

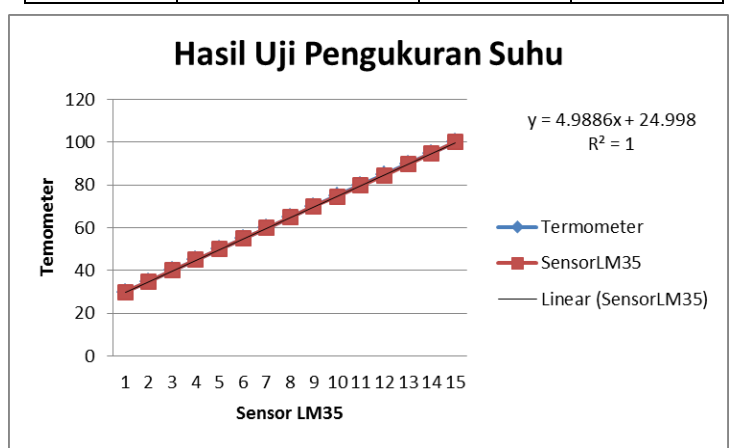

Gambar 8. Hasil Uji Pengukuran Suhu

Dari hasil pengujian dengan membandingkan dua alat ukur yakni menggunakan thermometer dengan sensor suhu LM35, menunjukan bahwa terdapat selisih rata-rata $1^{\circ} \mathrm{C}$, namun dari hasil perhintungan menggunakan metode regresi menunjukan prosentase besarnya variabilitas dalam data adalah $\mathrm{y}=4.9886 \mathrm{x}+24.998$ dimana hubungan $x$ adalah sensor LM35 dan $y$ adalah thermometer, maka keeratan hubungan antara $x$ dan y sangat kuat yakni $R^{2}=1$

\subsection{Hasil Pengujian Kadar Alkohol}

Sampel pengujian kadar alkohol diambil dari hasil detilasi minuman beralkohol, dimana sampel yang didapat dari petani rata-rata 35\% - 40\%. Hasil pengukuran kadar alkohol yang dilakukan di laboratorium menggunakan alkoholmeter adalah $35 \%$. Kemudian minuman beralkohol ini dibuat 10 jenis sampel dengan nilai konsentrasi terhadap kadar alkohol masing-masing berbeda $10 \%$. Kemudian sampel ini diukur dengan menggunakan alkoholmeter dan sensor MQ-3, data hasil pengujian tersebut dapat dilihat pada table dibawah ini. 
Tabel 2. Hasil Pengujian Kadar Alkohol

\begin{tabular}{|l|c|c|c|}
\hline No & $\begin{array}{c}\text { Pengenceran } \\
\text { Menggunakan } \\
\text { air (\%) }\end{array}$ & $\begin{array}{c}\text { Kadar } \\
\text { Alkohol } \\
\text { Alkohol } \\
\text { meter (\%) }\end{array}$ & $\begin{array}{c}\text { Kadar } \\
\text { Alkohol } \\
\text { Sensor } \\
\text { MQ-3 (\%) }\end{array}$ \\
\hline 1 & 100 & 0 & -4 \\
\hline 2 & 90 & 2 & 3 \\
\hline 3 & 80 & 4 & 5 \\
\hline 4 & 70 & 7 & 9 \\
\hline 5 & 60 & 10 & 13 \\
\hline 6 & 50 & 14 & 15 \\
\hline 7 & 40 & 17 & 18 \\
\hline 8 & 30 & 21 & 22 \\
\hline 9 & 20 & 25 & 26 \\
\hline 10 & 10 & 30 & 33 \\
\hline 11 & 0 & 35 & 37 \\
\hline
\end{tabular}

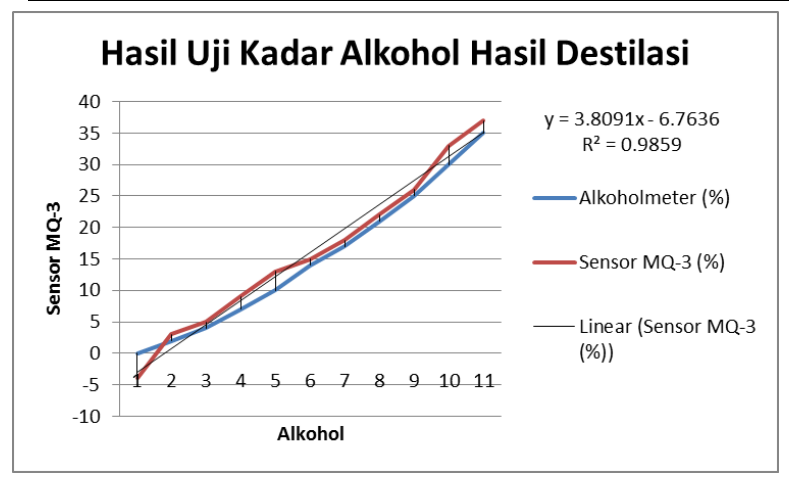

Gambar 9. Hasil Uji Pengukuran Alkohol

Dari hasil pengujian dengan membandingkan dua alat ukur yakni menggunakan alkoholmeter dengan sensor alkohol MQ-3, menunjukan bahwa terdapat selisih rata-rata $2 \%$, namun dari hasil perhintungan menggunakan metode regresi menunjukan prosentase besarnya variabilitas dalam data adalah $y=3,8091 x+6,7636$ dimana hubungan $x$ adalah sensor LM35 dan y adalah thermometer, maka keeratan hubungan antara $\mathrm{x}$ dan y kuat yakni $R^{2}=0.9859$

\section{Kesimpulan}

Dari penelitian yang telah dilakukan mengenai rancang bangun alat ukur suhu dan kadar alkohol dapat ditarik kesimpulan sebagai berikut:
1. Sensor LM35 dapat mendeteksi perubahan suhu dengan akurat dengan fungsi tranfer sensor adalah $\mathrm{y}=4.9886 \mathrm{x}+24.998\left(\mathrm{R}^{2}=1\right)$

2. Sensor MQ-3 dapat digunakan untuk mendeteksi perubahan kadar alkohol pada cairan.

3. Fungsi transfer sensor adalah $\mathrm{y}=3.8091 \mathrm{x}-6.7636$ $\left(\mathrm{R}^{2}=0.9859\right)$

4. Kesalahan relatif rata-rata dari alat yang dihasilkan adalah $3,25 \%$.

\section{Daftar Pustaka}

Ade Vikri Satria, Wildian. 2013. Rancang bangun alat ukur kadar alkohol pada cairan Menggunakan Sensor MQ-3 berbasis Mikrokontroler AT89s51. Jurnal Fisika Unand Vol.2, No.1

Budiastra, I Nyoman , I Made Hendry Jayamiharja dan I.G. Agung Mulya Negara. 2009. Rancang Bangun Alat Ukur Kadar Alkohol Pada Minuman Berbasis Mikrokontroler AT89S51. Jurnal Teknologi Elektro. 8(1):31-37

Hanwei Electronics Co., Ltd. 2002.MQ-3 Datasheet.

Growth Energy. 2010. http://www.drivingethanol.org/ethanol lane.ht $\underline{\mathrm{ml}}$

Gylbert H.N. Simatupang, Sherwin R.U.A. Sompie, Novi M. Tulung. 2015. Rancang Alat Pendeteksi Kadar Alkohol Melalui Ekhalasi Menggunakan Sensor TGS2620 Berbasis Mikrokontroler Arduino UNO. e-jurnal Teknik elektro dan computer Vol 4, No.7

Layuck, J. R. 2012. Captikus Kini Bisa Jadi Bahan Baku Alkohol Teknis. http://regional.kompas.com/read/2012/05/3 0/21315753/Captikus.Kini.Bisa.Jadi.Bahan.B aku.Alkohol.Teknis [30 Mei 2012]

National Semiconductor. 2000. LM35 Datasheet.

Samadikun, Samaun, Reka Rio dan Tati Mengko. 1989. Sistem Instrumentasi Elektronika. ITB, Bandung.

Texas Instrument. 2013. AN-460 LM34/LM35 Precision Monolithic Temperature Sensors. Revised Version. Texas, Texas Instrument Incorporated. 